\title{
Analysis on dynamic failure behaviors of steel double-layer cylindrical latticed shells supported by steel columns used in a gymnasium under earthquake action
}

\author{
Mingzhi Gao ${ }^{1, \text { a }}$, Haiwang Li ${ }^{1, b}$, Jing Liu ${ }^{1, \mathrm{c}}$ \\ Department of architecture and civil engineering, Taiyuan University of Technology, \\ 79, Yingzexi Street, Taiyuan, 030024, China \\ asandwich8723@163.com, 'Ihwtut@126.com(corresponding author) \\ ccimeng2005@163.com
}

\begin{abstract}
Keywords: Strong earthquake action, steel double-layer cylindrical latticed shells, Elasto-plastic dynamic response, Plastic hinge, Seismic performance
\end{abstract}

\begin{abstract}
In this paper, the analysis on dynamic failure behaviors of steel double-layer cylindrical latticed shells supported by steel rectangle columns in a gymnasium with the function of earthquake victims shelter under disaster earthquake is carried out under EL-centro wave with SAP2000, and the appraisal results on their anti-failure performances are presented under strong earthquake action based on the plastic-hinge theory. In the analyses, the geometric and material nonlinear effects are considered simultaneously. The plastic development level of the rods, the deformed shape and the failure type and the ductility are estimated.The results show that Under EL earthquake wave input in the combine direction of $\mathrm{Y}+0.85 \mathrm{X}+0.65 \mathrm{Z}$, the structure's elastic limitation PGA is $277 \mathrm{gal}$. Its failure model is the elasto-plastic dynamic buckling and its critical PGA is 692 gal. its displacement ductility coefficient is 4.33 , and the ratio of its bars with plastic hinge appearing for ultimate critical state is $26.5 \%$. All results show the structure have good deformed capacity and energy-dissipation capacity before bucking.
\end{abstract}

\section{Introduction}

Double-layer latticed cylindrical shells with their structural advantages and good seismic performance are widely used in large span buildings in China. Previous recent disastrous earthquakes show that the large span public buildings were used as earthquake victim shelters and disaster relief headquarter sites ${ }^{[1]}$. So the large span public buildings newly designed are gradually required to have the function of earthquake shelters. In order to work safely during disastrous earthquakes, the structures of these buildings are required to be designed under strong earthquake action larger than the official seismic major fortification earthquake level. Therefore the appraisal method on their anti-collapse performances under strong earthquake action is needed to be studied. In this paper, the elasto-plastic dynamic analysis on dynamic failure behaviors of steel double-layer cylindrical latticed shells used in a gymnasium is carried out and appraisal results on their anti-failure performances are presented under strong earthquake action based on the plastic-hinge theory ${ }^{[2]}$.

\section{Analysis Model}

A sports practice gymnasium with plane size of $30 \times 50.4 \mathrm{~m}$ and cornice elevation level of $9 \mathrm{~m}$ is shown in Fig.1. Its roof structure is a double-layer cylindrical latticed shell with rise-span ratio of 0.2 supported by circumjacent steel rectangle column. The gymnasium structure is designed firstly according to the current national standards ${ }^{[3,4]}$ with official seismic fortification level of 8 degree $(0.2 \mathrm{~g})$ and site classification of type III, design reference period of 50 years, design characteristic period of ground motion of $0.45 \mathrm{~s}$. Its peak ground acceleration for the small and the major earthquake is respectively 70 gal and 400 gal $^{[4]}$. The damp is taken as Rayleigh with the damping ratio of 0.02 or 0.05 for elasticity or elasto-plasticity. The material adopts bilinear elastic-plastic 
material model with the density $7850 \mathrm{Kg} / \mathrm{m}^{3}$, elasticity modulus $2.06 \mathrm{Gpa}$, tangent modulus $6.18 \mathrm{GPa}$, the Poisson ratio 0.3 , and the yield strength $235 \mathrm{MPa}$. The top chord cross section sizes are among $\varphi 83 \times 3.5,95 \times 4.5$ and $\varphi 133 \times 4.5$, the lower chord cross section sizes are among $\varphi 76 \times 4.5$ and $\varphi 95 \times 4.5$, the web member cross section sizes are $\varphi 76 \times 3.5, \varphi 83 \times 3.5$. The nonlinear analysis on the spatial truss under EL-Centro wave is carried out with plastic hinge method by SAP2000. The generalized force-displacement relation for the plastic hinge defined in the members of the structure

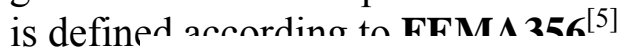
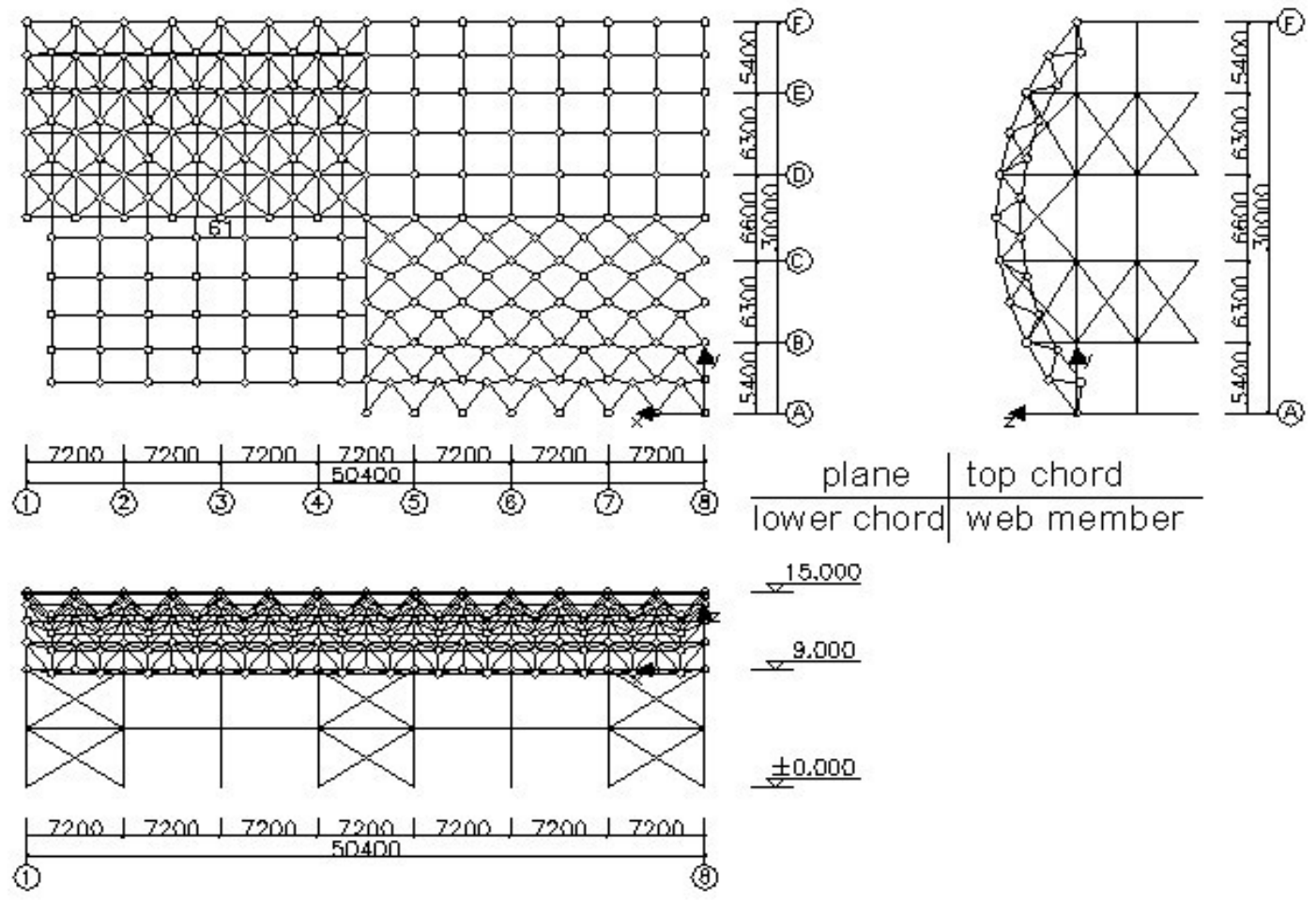

Fig. 1 Structure layout

(The number shown in the figure is the feature node)

\section{Results and Analysis}

Nonlinear time history calculations on the model are carried out by SAP2000 with El-Centro wave chosen as earthquake wave applied in the combine direction of $\mathrm{Y}+0.85 \mathrm{X}+0.65 \mathrm{Z}$. The initial condition for each time-history calculation is the deformed state of the structure under the whole dead load and the half live load. Many calculations with different peak value of the input earthquake wave applied to the structure designed according to the official Seismic fortification level(shorted as SFL) are carried out to find two limit conditions for the structure. The first is the elastic limitation; the second is critical failure state. The number and the distribution of the plastic hinge are provided in Tab.1. The failure model is shown in Fig.2. The relationship curve between the maximum displacement of node 61 and peak ground acceleration (shorted as PGA) are respectively shown in Fig.3. Displacement ductility coefficient of the structure is listed in Tab. 2. Displacement-time curve of feature node 61 in 277gal, 692 gal and 693 gal is shown in Fig.4.

Tab.1 The plasticity development level in 277 and 692al

\begin{tabular}{|c|c|c|c|c|c|c|c|c|c|}
\hline \multirow{2}{*}{$\begin{array}{c}\text { PG } \\
\text { A } \\
\text { /gal }\end{array}$} & Region & B-IO & IO-LS & LS-CP & CP-C & C-E & $\begin{array}{c}\text { Region } \\
\text { percentage } \\
(\%)\end{array}$ & $\begin{array}{c}\text { Total } \\
\text { number of } \\
\text { plastic } \\
\text { hinges }\end{array}$ & $\begin{array}{c}\text { Total } \\
\text { percenta } \\
\text { ge(\%) }\end{array}$ \\
\hline \multirow{2}{*}{277} & $\begin{array}{c}\text { Top } \\
\text { chord }\end{array}$ & 1 & - & - & - & - & 0.33 & & \\
\cline { 2 - 10 } & $\begin{array}{c}\text { Lower } \\
\text { chord }\end{array}$ & - & - & - & - & - & 0.00 & 1 & 0.06 \\
\hline
\end{tabular}




\begin{tabular}{|c|c|c|c|c|c|c|c|c|c|}
\hline & $\begin{array}{l}\text { Web } \\
\text { member }\end{array}$ & - & - & - & - & - & 0.00 & & \\
\hline & $\begin{array}{c}\text { Lower } \\
\text { structure }\end{array}$ & - & - & - & - & - & 0.00 & & \\
\hline \multirow{4}{*}{692} & $\begin{array}{c}\text { Top } \\
\text { chord }\end{array}$ & 10 & 30 & - & 1 & 39 & 26.32 & \multirow{4}{*}{413} & \multirow{4}{*}{26.5} \\
\hline & $\begin{array}{l}\text { Lower } \\
\text { chord }\end{array}$ & 10 & 39 & 3 & 3 & 50 & 41.01 & & \\
\hline & $\begin{array}{c}\text { Web } \\
\text { member }\end{array}$ & 33 & 82 & 12 & 3 & 83 & 35.31 & & \\
\hline & $\begin{array}{c}\text { Lower } \\
\text { structure }\end{array}$ & 5 & 6 & - & - & 4 & 9.5 & & \\
\hline
\end{tabular}

Note: “—” indicates that no plastic hinge

Tab. 2 Displacement ductility coefficients

\begin{tabular}{|c|c|c|c|}
\hline Critical PGA (gal) & $\begin{array}{c}\text { Node } \\
\text { number }\end{array}$ & $\begin{array}{c}\text { Absolute } \\
\text { displacement }\end{array}$ & Yield Displacement ratio \\
\hline 277 & 61 & 45.53 & 1.00 \\
\hline 692 & 61 & 197.32 & 4.33 \\
\hline
\end{tabular}

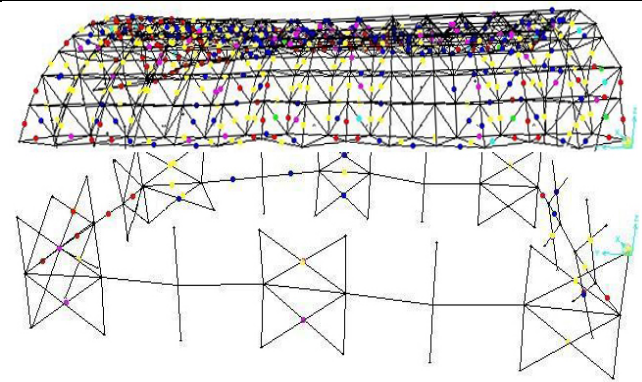

Fig2 The failure mode and the plastic hinge distribution

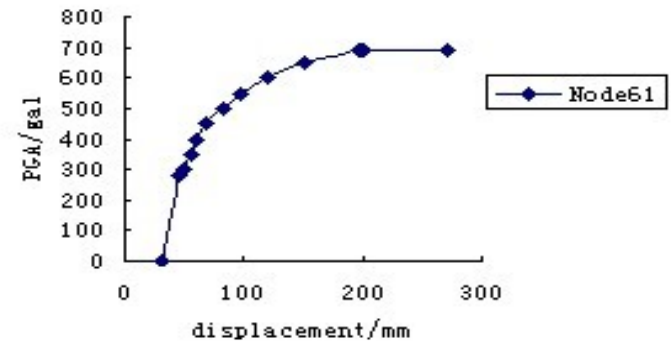

Fig3 The horizontal displacement of the feature node 61 - PGA curve

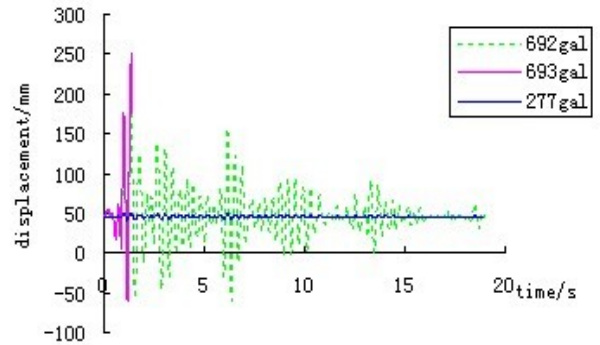

Fig.4 Disp. time history curves of Node 61

According to Tab.1 2 and Fig.2 4, the results can be concluded as follows:

The elastic limitation PGA for three direction input is $277 \mathrm{gal}$. It is much larger than the PGA of the official SEL for small earthquake (70gal).

According to the B-R criterion ${ }^{[6,7]}$, the failure model of the structure under the earthquake wave action is the elasto-plastic dynamic buckling in area between $2 \sim 7$ axis of the structure. Its critical PGA for this direction input is 692 gal. It is much larger than the PGA of the official SEL for major 
earthquake (400gal).

The displacement ductility coefficient is 4.33 for the structure, and the ratio of its bars with plastic hinge appearing for ultimate critical state is $26.5 \%$ when EL earthquake waves applied on the structure, so the development of the plastic hinges is sufficient. The ratio of its maximal failure node 61 vertical displacement and its short span is $1 / 182$, The ratio of its maximal failure node horizontal displacement and its columns is $1 / 55$.

All members in the E stage are in compression state, which gradually develop to whole shell bucking.

All results about show the structure have good deformed capacity and energy-dissipation capacity before bucking under El earthquake wave.

\section{Summary}

Under EL earthquake wave input in the combine direction of $\mathrm{Y}+0.85 \mathrm{X}+0.65 \mathrm{Z}$, the structure's elastic limitation PGA is 277 gal. Its failure model is the elasto-plastic dynamic buckling and its critical PGA is 692 gal. its displacement ductility coefficient is 4.33 , and the ratio of its bars with plastic hinge appearing for ultimate critical state is $26.5 \%$, so the development of the plastic hinges is sufficient. The ratio of its maximal failure node 61 vertical displacement and its short span is $1 / 182$, The ratio of its maximal failure node horizontal displacement and its columns is $1 / 55$. All members in the E stage are in compression state, which gradually develop to whole shell bucking.

All results about show the structure have good deformed capacity and energy-dissipation capacity before bucking under El earthquake wave.

\section{Acknowledgements}

This project is financially supported by National Natural Science Foundation of China(50878137); Key Project Foundation of Shanxi Province (20080321086) and Shanxi Province Foundation for Scholar Returned from Abroad (2009-26).

\section{References}

[1] H.W. Li, H.S. Zhao, Y.J. Zhao: Study on Planning for the Indoor-earthquake-shelter in City and Town. (Advanced Science Letters), USA, 2011, Vol. 4, pp.2654-2665.

[2] Civil King Software Technology Co., Ltd. China institute of Building Standard Design \& Research. Usage Guide to Structure Analysis Program SAP2000 Chinese Edition [CP] (China communications press, China, 2006), p.460.

[3] JGJ7-2010 Technical specification for space frame structures [S]. (China architecture \& building press, Beijing, 2010)

[4] GB50011-2010(2010 edition) Code for seismic design of buildings[S]. (China architecture \& building press, Beijing, 2010).

[5] FEM 356 The Seismic Rehabilitation of Buildings[S]. Federal Emergency Management Agency,2000.

[6] S.S. Zhao and C. Xin: Dynamic stability of grid structure [M] (Beijing, Science Press, 1999).

[7] H.W. Li, J.X. Li, F. Zhi, F. Ma and D.Q. Qin: Proceedings of the 6th International Conference on Computation of Shell and Spatial Structures IASS-IACM (Cornell University, Ithaca, NY, USA, May 28-31, 2008) 